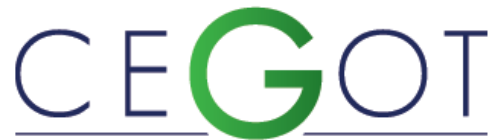

Centro de Estudos de Geografia e Ordenamento do Território

Geografia e Ordenamento do Território, Revista Eletrónica Centro de Estudos de Geografia e Ordenamento do Território http://cegot.org

FARIAS, MONIQUE

Núcleo de Pesquisas Aplicadas ao Desenvolvimento Regional (NUPAD)/ Universidade do Estado do Pará (UEPA)

Tv. Dr. Enéas Pinheiro, 2626, 66095-015, Belém/ PA, Brasil adm.moniquefarias@gmail.com

Beltrão, NoRMA

Programa de Pós-Graduação em Ciências Ambientais/Núcleo de Pesquisas Aplicadas ao Desenvolvimento Regional

(NUPAD)/ Universidade do Estado do Pará (UEPA)

Tv. Dr. Enéas Pinheiro, 2626, 66095-015, Belém/ PA, Brasil

Inormaelybeltrao@gmail.com

SANTos, Cleber

Centro de Ciência do Sistema Terrestre (CCST)/ Instituto Nacional de Pesquisas Espaciais (INPE)

Av. dos Astronautas, 1.758 - Jardim da Granja, 12227-010, São José dos

Campos / SP, Brasil

cleberufpa@yahoo.com.br

SILVA, CHRISTIAN

Programa de Pós- Graduação em Geografia/ Grupo Acadêmico

a Produção do Território e Meio Ambiente na Amazônia

(GAPTA/CNPq)/ Universidade Federal do Pará (UFPA)

Rua Augusto Corrêa, 1, Campus Básico, 66075-110, Belém/ PA, Brasil

cnsgeo@yahoo.com.br

\title{
Potencial do Cadastro Ambiental Rural (CAR) no controle do desmatamento em assentamentos no município de Novo Repartimento (PA)
}

Potential of the Rural Environmental Registry (CAR) in the Control of Deforestation in

Settlements in the Municipality of Novo Repartimento (PA)

Referência: Farias, Monique et al. (2018). Potencial do Cadastro Ambiental Rural (CAR) no controle do desmatamento em assentamentos no município de Novo Repartimento (PA). Revista de Geografia e Ordenamento do Território (GOT), n. ${ }^{\circ} 14$ (setembro). Centro de Estudos de Geografia e Ordenamento do Território, p. 179-199, dx.doi.org/10.17127/got/2018.14.007

\section{RESUMO}

Ao avaliar a dinâmica do desmatamento em $15 \%$ dos assentamentos federais do Estado do Pará, durante cinco anos, detectou-se haver proporcionalmente mais desmatamentos no interior dos assentamentos do que na área que os circunscreve. Assim, tem-se o Cadastro Ambiental Rural (CAR) como uma contribuição para a compreensão tanto da expansão da fronteira quanto daquilo que na literatura se denomina Uso e Mudança na Cobertura da Terra, oferecendo um meio eletrônico que permite o cruzamento de informações do desmatamento com o mapa fundiário, apresentando a situação das propriedades ou posses rurais e sua relação com cortes na floresta. Este trabalho tem como objetivo analisar a efetividade do CAR como política ambiental em projetos de assentamentos no município de Novo Repartimento, visando compreender os fatores associados ao avanço do desmatamento e as políticas públicas formuladas para contê-lo.

Palavras-chave: Conservação; Política; Registro; Regularização. 


\section{ABSTRACT}

Assessing the dynamics of deforestation in $15 \%$ of the federal settlements in Pará State for five years, it was detected proportionally more deforestation within the settlements than in the area that circumscribes them. Thus, there is the Rural Environmental Registry (CAR) as a contribution to understanding the Frontier expansion and the land-use and land-cover change, offering an electronic document that allows the crossing of deforestation information with the land map, showing the situation of rural properties or possessions and their relation to forest felling. This work aims to analyze the effectiveness of CAR as environmental policy on settlement projects in the city of Novo Repartimento, in order to understand the factors associated with the advance of deforestation and the public policies formulated to contain it.

Keywords: Conservation; Policy; Registry; Regularization.

\section{Introdução}

Sendo a Amazônia Brasileira biogeograficamente heterogênea, os impactos antropogênicos sofridos resultam de uma enorme variedade de padrões de desmatamento associados a diferentes atores e formas de uso da terra. Dada a complexidade e dinâmica desta região, existem muitas iniciativas voltadas ao controle e prevenção do desmatamento (DINIZ et al., 2015; RODRIGUES-FILHO et al., 2015).

Assunção et al. (2015) expõem que as políticas de conservação destinadas a controlar e prevenir o desmatamento na Amazônia passaram por revisões significativas durante os anos 2000, marcadas por dois pontos de grande relevância: o lançamento do Plano de Ação para a Prevenção e Controle do Desmatamento na Amazônia Legal (PPCDAm) em 2004, integrando ações entre diferentes instituições governamentais e introduzindo procedimentos inovadores de controle, monitoramento ambiental e gestão territorial; e a implementação de melhorias na tecnologia de monitoramento e disponibilidade de dados anuais via satélite sobre o desmatamento em escala municipal, possibilitando o estudo de sua dinâmica, o que contribui para a compreensão de como incentivos e políticas moldam a ação do desmatamento (HARGRAVE e KIS-KATOS, 2013).

No entanto, de acordo com Pacheco et al. (2010), há uma tensão crescente nas políticas públicas aplicadas pelos governos da Região Amazônica uma vez que, por um lado, algumas 
políticas tentam facilitar o crescimento econômico relacionado com a promoção do agronegócio, juntamente com maiores investimentos em desenvolvimento de infraestrutura e expansão de uma agricultura mais competitiva ligados aos mercados de exportação; o cumprimento das leis ambientais, cujo objetivo é proteger as florestas e meios de subsistência dos povos locais baseadas no uso dos recursos florestais, e as políticas para conservação de florestas são os instrumentos implementados junto a tentativas de reconhecimento de direitos de posse de povos indígenas locais e outros.

Desde as ondas de migração causadas pelos poderes públicos para sertões amazônicos da década de 1970, quando colonos foram obrigados a desmatar para demonstrar a posse da terra, a política do Brasil passou de uma rápida colonização fronteira aos regimes de reforma agrária, uma estratégia para reverter a tendência de concentração de terras em grandes latifúndios (SCHNEIDER e PERES, 2015). Caviglia-Harris e Harris (2011) declaram que os formuladores de políticas na Amazônia brasileira enfrentam o desafio de atender os objetivos ambientais e de desenvolvimento de cidades e vilas que continuam a enfrentar a pressão da migração, resultando em assentamentos projetados de acordo com um modelo que não levava em consideração a paisagem biofísica, as restrições de diferentes regiões biofísicas e os subsequentes impactos ambientais, acarretando impactos negativos na cobertura da terra e transformação do uso da terra. Neste sentido, Song et al. (2015) afirmam que, se resumir em uma lista os processos de uso da terra que muitas vezes são omitidos em muitos ou todos os estudos existentes, os projetos de assentamentos seria um deles.

Para avaliar essa situação, este trabalho destaca o estado do Pará, o qual detém 1055 projetos de assentamentos e 221804 famílias instaladas, constituindo a maior área de assentamentos entre os estados Amazônicos. Em estudo desenvolvido por Calandino et al. (2012), ao avaliar a dinâmica do desmatamento em 15\% dos assentamentos federais do Estado do Pará, durante cinco anos, detectou-se haver proporcionalmente mais desmatamentos no interior dos assentamentos do que na área que os circunscreve.

Explica Acselrad (2010) que a construção da Usina Hidrelétrica de Tucuruí, no sul do estado do Pará, inundou, em 1984-1985, 2600 km² de floresta das margens do rio Tocantins, incluindo parte da reserva dos índios Parakanã e alguns núcleos urbanos, deslocando compulsoriamente de suas áreas de moradia e de trabalho cerca de 10 mil famílias. 
A inundação do Reservatório de Tucuruí e o processo de relocação geraram indignação na população, que se viu obrigada a viver em acampamentos improvisados ou em superlotados imóveis de Novo Repartimento - núcleo urbano, na época, em implantação (ACSELRAD, 1991). Dedicada, em sua maioria, às atividades extrativas, parte dessa população foi relocada em loteamentos implantados às margens do reservatório. Lançados bruscamente no trabalho agrícola em áreas cuja paisagem natural desconheciam, os relocados não puderam estabilizar-se economicamente, o que favoreceu a reconcentração fundiária e o desmatamento (ACSELRAD, 2010). Atualmente, Novo Repartimento possui 31 projetos de assentamentos rurais, compreendidos em uma área total de 376 767,90 hectares, representando $24,5 \%$ da área total do município.

Sob o aspecto científico, pode-se considerar a contribuição que este estudo traz em virtude da escassez de estudos que abordem a questão ambiental nas ações da Política Nacional de Reforma Agrária em níveis estadual e municipal, carecendo assim de novos trabalhos que forneçam subsídios para a elaboração de políticas públicas condizentes com esta realidade. Alega-se frequentemente que a participação municipal é imprescindível para o combate ao desmatamento. O município representa a menor esfera de governo no Brasil, e tem autonomia relativa em finanças, política e gestão. Essa autonomia, apesar de não representarem auto-suficiência, afeta formulação e implementação de políticas públicas. Desmatamento na Amazônia reflete os parâmetros socioeconômicos de cada município (DIAS et al., 2015).

Por fim, este trabalho tem como objetivo analisar a efetividade do Cadastro Ambiental Rural (CAR) como política ambiental em projetos de assentamentos no município de Novo Repartimento, tendo em vista compreender os fatores associados ao avanço do desmatamento e as políticas públicas formuladas para contê-lo, proporcionando o desenvolvimento agrário de forma sustentável. 


\section{Metodologia}

\subsection{Descrição da Área de Estudo}

O município de Novo Repartimento integra a Região de Integração (RI) Lago de Tucuruí, localizada na Região Sudeste do Estado do Pará, entrecortada pelo Rio Tocantins e pelas rodovias BR-230 (Rodovia Transamazônica) e PA-150. Abrange uma área de 3993788 hectares, compreendendo também os municípios de Breu Branco, Goianésia do Pará, Itupiranga, Jacundá, Nova Ipixuna e Tucuruí, o que corresponde a aproximadamente 3,20\% do território paraense. Esta região é conhecida por abrigar a Usina Hidrelétrica de Tucuruí (UHT), a qual deu origem a municípios devido ao deslocamento e reassentamento de povoados inteiros, inclusive de aldeias indígenas (para a construção da barragem) e outros cresceram em densidade populacional decorrente da atração econômica que o processo de edificação da usina exerceu na época (IDESP, 2013).

Segundo Castro et al. (2010), e pautados nos dados obtidos no Censo Demográfico 2010 (IBGE), a cidade de Tucuruí exerce a função de polo regional. Possui a maior população da região, 107189 habitantes, 27\% da população da região e a maior densidade demográfica com 51,16 habitantes por hectare. O município de Novo Repartimento se destaca em termos de área territorial, com 1539800 hectares, 38,5 \% da área territorial total da região, e apresenta a segunda maior população da região. Rocha (2015) expõe que, demograficamente, houve mudança no tamanho, no ritmo de crescimento, na distribuição espacial e na estrutura da população desta região em decorrência da construção da Usina Hidrelétrica de Tucuruí.

No contexto econômico, destaca-se a atuação na área de serviços, indústrias e agropecuária. Novo Repartimento figura entre os dez municípios de maior destaque na produção pecuária que, juntos, respondem por $81 \%$ da produção total do estado. 0 município de São Félix do Xingu desponta como o de maior rebanho bovino do Pará (2 282445 cabeças, correspondendo a 11,91\% do rebanho estadual). Chama-se atenção para o fato de que Novo Repartimento, 2. colocado no ranking estadual, possui um rebanho equivalente a $37 \%$ ao daquele município (855 mil cabeças), representando $4,46 \%$ do efetivo estadual (FAPESPA, 2015). 
O município abriga a Terra Indígena Parakanã, com área de 337930 hectares, sendo 298191 hectares de área de florestas em 2014 (88\% de sua área total); apresenta ainda 3 Unidades de Conservação (UC's) e 31 Projetos de Assentamentos (PA's) (IMAZON, 2014).

Para esse estudo, foi dada ênfase aos 31 projetos de assentamentos rurais, compreendidos em uma área total de 376767,90 hectares, representando $24,5 \%$ da área total do município (Figura 1).

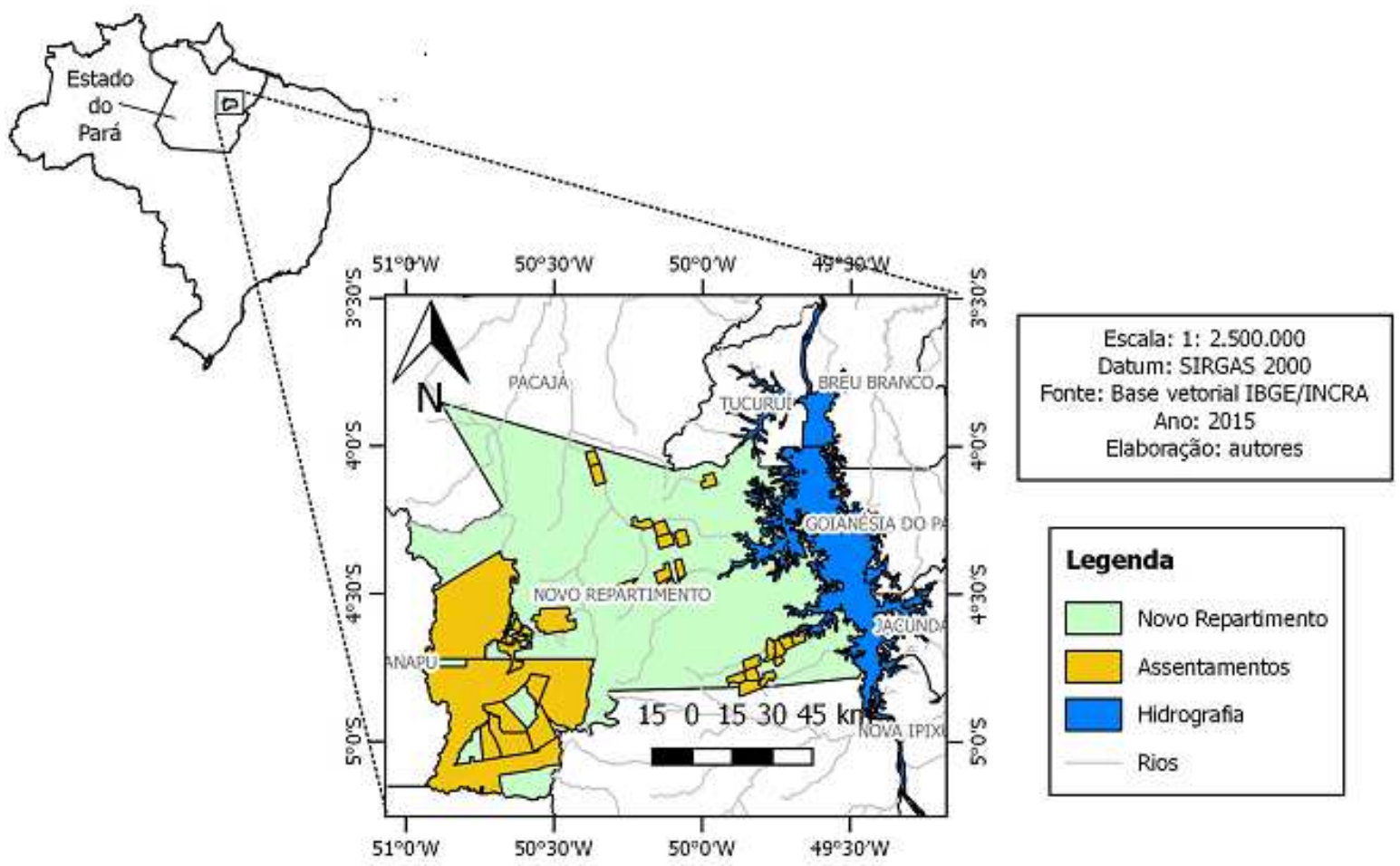

Figura 1 - Projetos de Assentamentos em Novo Repartimento (PA)

Fonte: IBGE/ INCRA, 2015.

\subsection{Coleta de Dados}

Os aspectos teóricos e conceituais sobre a problemática ambiental em áreas de projetos de assentamentos foram obtidos por meio da análise de artigos científicos nacionais e internacionais, legislações e relatórios e publicações institucionais.

Os dados demográficos da distribuição anual da população nos municípios foram colhidos dos censos demográficos e estimativas intercensitárias, realizados pela Fundação Instituto Brasileiro de Geografia e Estatística (IBGE). 
As informações sobre o Cadastro Ambiental Rural (CAR) são oriundas do Sistema Integrado de Monitoramento e Licenciamento Ambiental - Modulo Público (SIMLAM Público), da Secretaria de Estado de Meio Ambiente e Sustentabilidade (SEMAS/PA), e base cartográfica utilizada também foi fornecida pela referida Secretaria.

Os dados sobre o desmatamento na área de estudo foram obtidos através do Portal do Programa de Cálculo do Desmatamento da Amazônia (PRODES/INPE). Esclarecem Piketty et al. (2015) que o método PRODES mede a extensão do desmatamento anual na Amazônia Legal a partir de uma resolução espacial média (tamanho do pixel: 0,36 ha), compreendendo um sistema de classificação baseado na abordagem de modelo de mistura espectral, e usando dados de sensoriamento remoto (imagens de satélite Landsat 5). A base de dados espaciais relativa às informações de assentamentos no Estado do Pará e no município de Novo Repartimento foram obtidas do Instituto Nacional da Colonização e Reforma Agrária (INCRA). A partir das bases cartográficas mencionadas, foram selecionados os shapes de cada Plano de Informação (desmatamento, assentamentos e CAR) para o município de Novo Repartimento para, finalmente, realizar análise espacial por geoprocessamento utilizando o Software QGIS 2.8.

\section{Dinâmica do uso da terra e impactos do desmatamento na}

\section{Amazônia}

O desmatamento na Amazônia brasileira é um problema amplamente reconhecido, com múltiplas consequências negativas em âmbito local, regional e global, tais como perda de biodiversidade, degradação do solo, e mudança climática (DINIZ et al., 2015). Serviços ecossistêmicos mundiais estão claramente ameaçados pelo desmatamento associado à ocupação humana e ao desenvolvimento econômico da Amazônia brasileira. No entanto, o prognóstico para o bem-estar socioeconômico dos habitantes permanece obscuro. Em uma regularidade empírica que tem sido chamado o padrão de expansão e recessão ou a maldição dos recursos, a exploração dos recursos naturais está associada a ganhos de curto prazo no bem-estar que se dissipam ao longo do tempo (Caviglia-Harris et al., 2016) . 
Oliveira- Júnior et al. (2010) que, entre os fatores apontados como explicativos da heterogeneidade do espaço do desmatamento estão os aspectos relacionados às características naturais (relevo, clima, solo, condições de acesso); como também, as diferenças e semelhanças das dinâmicas econômicas das atividades produtivas dominantes, que acabaram por se traduzir em diferenças quanto ao padrão de uso do solo, ocupação e, por essa via, das forças impulsionadoras do desmatamento em cada caso. Ressalta-se que a conformação territorial e ocupacional está também relacionada, direta ou indiretamente, aos meios de acesso à região e como estes vão servindo de canalizadores do processo migratório, do crescimento demográfico e dos adensamentos urbanos. Neste particular, aparecem as iniciativas de colonização públicas e privadas.

Diniz et al. (2009) complementam esse rol destacando que, entre as causas primárias mais significativas, estariam a expansão da agropecuária, seja da cultura temporária, seja da cultura permanente, e a pecuária de caráter eminentemente extensivo; a extração da madeira para diversos usos e fins comerciais e a infraestrutura existente, que permite 0 acesso, o deslocamento e a fixação dos diferentes agentes que integram as atividades econômicas da agropecuária e de exploração florestal, especialmente de madeira. Neste último caso, a infraestrutura e a logística de transporte, bem como as diferentes modalidades de colonização, inclusive os assentamentos populacionais, serviriam como fatores de atração de contingentes populacionais e poderiam ser apontados como causas primárias.

Para Rosa et al. (2015), a era moderna do desmatamento na Amazônia começou nos anos de 1960 e 1970 com esquemas de colonização implementados pelo governo brasileiro. Os projetos de colonização e integração nacional criaram os alicerces para a implantação dos assentamentos na Amazônia. A maior parte das famílias que migraram para a região foi motivada pela oferta de terras e crédito subsidiado, e foram distribuídas, em sua maioria, em assentamentos do Incra, concentrados ao longo da rodovia Transamazônica, no Estado do Pará, e no entorno da BR-364 em Rondônia (BRANDÃO JÚNIOR eSILVA JÚNIOR, 2006) .

Os processos de colonização na Amazônia têm atraído considerável atenção nos últimos trinta anos, principalmente devido ao desmatamento associado à apropriação da terra (BATISTELLA e MORAN, 2005). Mello- Théry (2011) destaca que os projetos de assentamentos já implantados, em sua maioria, circundam terras indígenas e acompanham 
o traçado de rodovias, exercendo uma forte pressão sobre as mesmas. Além disso, o problema se intensifica quando se agregam as áreas propostas pela política nacional de conservação da biodiversidade com as terras arrecadadas pelo INCRA, que cobrem superfície bem maior.

O uso da terra, para Silva et al. (2017), é definido em função das atividades desenvolvidas em determinada área que, no caso de propriedades rurais, são voltadas principalmente para o estabelecimento de culturas e criação de animais, além de moradia e recreação. Estima-se que as mudanças nos usos da terra sejam responsáveis por $75 \%$ das emissões de gases de efeito-estufa no Brasil, com especial destaque para as queimadas e o desmatamento no Cerrado e na Floresta Amazônica, fatores esses associados à antropização.

Define Côrtes (2017) que o conceito de transformação da superfície da terra é organizado em dois componentes conectados: a cobertura da terra e o uso da terra. As classes de cobertura denotam o estado biofísico, como tipo de vegetação, água e outros elementos, e uma mudança de cobertura pode ocorrer por duas vias, a conversão ou modificação. A conversão é a mudança de uma classe de cobertura para outra (exemplo, floresta para terra cultivável). A modificação é a mudança na condição de uma categoria (exemplo, mudança da floresta por corte seletivo de árvores). Já as classes de uso denotam a maneira que os elementos biofísicos são utilizados, como assentamentos, cultivos, pastagem, recreação. A sua mudança envolve a transformação para outro uso ou a intensificação do uso atual. Um uso da terra pode corresponder a uma determinada classe de cobertura (por exemplo, uso pecuária e cobertura gramínea) ou mais (por exemplo, uso agrícola e cobertura de culturas e solo exposto). No mesmo sentido, a cobertura pode representar simultaneamente múltiplos usos (cobertura floresta: caça, exploração madeireira, extrativismo). A mudança no uso, em geral, causa mudança de cobertura, enquanto a cobertura pode se alterar mesmo quando o uso é o mesmo, como nos casos de manejo de exploração madeireira.

Nos dias atuais, existe uma concordância de que as alterações temporais no uso e cobertura da terra são as maiores condutoras de mudanças ambientais locais, regionais e globais, pelo fato de sua intervenção agir diretamente nas condições climáticas - a partir da remoção da cobertura vegetal original - nos ciclos biogeoquímicos, na biodiversidade e, o mais importante, sobre as atividades humanas (SANTOS et al., 2017). 


\section{Análise e discussão dos resultados}

\subsection{O CAR no Estado do Pará}

O CAR tornou-se um registro obrigatório para todos os imóveis agrários situados em áreas cadastráveis, ou seja, fora de Terras Indígenas (TI), Unidades de Conservação (UC) de domínio público e áreas urbanas, cujas informações ambientais nele contidas acabam compondo uma base de dados para controle, monitoramento, planejamento ambiental e econômico, e combate ao desmatamento. É por meio deste cadastro que os órgãos ambientais integrantes do Sistema Nacional do Meio Ambiente (SISNAMA) teriam acesso a informações confiáveis sobre a real situação, localização (georreferenciamento) e regularidade dos imóveis agrários no que concerne às áreas de interesse ambiental situadas dentro da propriedade ou da posse agrária (BARROSO e ALENCAR, 2014).

O estado do Pará apresenta área superior a 125 milhões de hectares, sendo que em torno de 58 milhões de hectares são passíveis de regularização por meio do Cadastro Ambiental Rural, não incluindo áreas pertencentes a Unidades de Conservação e Terras Indígenas.

A implementação do cadastramento é realizada por meio de georreferenciamento da área total da propriedade, aí incluindo as Áreas de Preservação Permanente (APPs), Área de Uso Alternativo do Solo (AUAS) e Áreas de Reserva Legal (ARL). Essas informações integrarão o Sistema de Licenciamento e Monitoramento Ambiental (SIMLAM), gerido pela Secretaria de Estado de Meio Ambiente e Sustentabilidade (SEMAS).

Em 2014, o Estado já dispunha de 65\% de área cadastrada, garantindo assim 37882541 hectares de registros de CAR constantes na base do SIMLAM. Desde início de sua vigência, percebeu-se grande avanço no procedimento de regularização ambiental dos imóveis rurais localizados no Estado do Pará. Isto se deu devido ao fortalecimento do uso de ferramentas de geotecnologia, o que agiliza o processo de criação do cadastro e proporciona informações mais confiáveis sobre o uso do solo do imóvel rural, além da realização de parcerias institucionais que promovam o processo de regularização ambiental de posses e propriedades rurais, tais como o Fundo Amazônia e The Nature Conservancy (TNC), bem como pela criação do Programa Municípios Verdes (PMV) e a realização de Termos de 
Ajustamento de Conduta junto ao Ministério Público Federal (MPF), iniciativas que promoveram o engajamento dos municípios paraenses para regularização dos registros dos imóveis rurais.

Assim, o CAR tornou-se, por diferentes motivos, imprescindível para os agentes econômicos e governamentais. Para muitas prefeituras, a implementação do CAR foi essencial para que vários municípios deixassem a crítica lista dos desmatadores permitindo, assim, a viabilidade da economia local. Sendo assim, nos últimos anos, o CAR deixou de ser um instrumento focado exclusivamente na sustentabilidade ambiental, tornando-se peça central para a sustentabilidade econômica dos municípios e do setor privado na região (AZEVEDO et al., 2014).

Em 07 de abril de 2016, por meio da Portaria SEMAS N.9 654, foi instituído o Sistema Nacional de Cadastro Ambiental Rural (SICAR), como o Sistema Oficial de Cadastro Ambiental do Estado do Pará, cuja aplicação fora denominada SICAR/PA. Coube à Secretaria de Estado de Meio Ambiente e Sustentabilidade (SEMAS) realizar a gestão da transição do Sistema Integrado de Monitoramento e Licenciamento Ambiental (SIMLAM) para o Sistema Nacional de Cadastro Ambiental Rural (SICAR).

Assim, o recebimento, gerenciamento e integração dos dados do CAR de todos os entes federativos foram transferidos para o Governo Federal, conforme disposto no Decreto n. ${ }^{\circ}$ 7 830, de 17 de outubro de 2012, o qual dispõe sobre o Sistema de Cadastro Ambiental Rural, o Cadastro Ambiental Rural, e estabelece normas de caráter geral aos Programas de Regularização Ambiental

\subsection{O instrumento do CAR na regularização ambiental dos assentamentos de Novo Repartimento}

Transformações significativas no campo econômico, social, político e ambiental ocorreram na região do Baixo Tocantins, área de jusante da maior barragem brasileira - a UHE-Tucuruí , localizada no município de Tucuruí, sudeste paraense. Não é a água represada em forma de reservatório da usina que caracteriza essa região, mas a dinâmica das transformações socioecológicas que ocorreram após o barramento do rio Tocantins e os conflitos socioambientais que emergiram a partir da segunda metade da década de 80 (SILVA, 2014). 
O município de Novo Repartimento, detentor de 1539800 hectares de área, dispõe de 1. 183160 hectares para regularização por meio do CAR. O número de imóveis rurais cadastrados no Sistema de Monitoramento e Licenciamento Ambiental (SIMLAM) somam 851 176, com uma área cadastrada em torno de 72\% da área total, ou seja, 72\% da área total cadastrável do município. Uma vez que este ainda não possui o mínimo de $80 \%$ (oitenta por cento) de seu território, excetuadas as unidades de conservação de domínio público e terras indígenas homologadas, com imóveis rurais devidamente monitorados por meio do CAR, não atende as exigências do Ministério do Meio Ambiente, ainda figurando na lista dos municípios que mais desmatam o Bioma Amazônico, mantendo também a classificação de "Município Embargado" junto ao Programa Municípios Verdes, a partir de análises realizadas até o ano de 2016.

A regularização ambiental de propriedades rurais em projetos de assentamentos está prevista no artigo 29 do Código Florestal vigente, realizada através do CAR, definindo ser obrigatório para todos os imóveis rurais, com a finalidade de integrar as informações ambientais das propriedades e posses rurais, compondo base de dados para controle, monitoramento, planejamento ambiental e econômico e combate ao desmatamento.

Com uma área total de 376768 hectares, os assentamentos de Novo Repartimento dispõem de um território cadastrável de 308535 hectares, ou seja, uma área passível de regularização ambiental (território sujeito ao cadastramento). As áreas consideradas cadastráveis são aquelas que abrigam assentamentos da Reforma Agrária, Territórios Quilombolas e Áreas de Proteção Ambiental (APAs). Por outro lado, áreas não cadastráveis são aquelas protegidas como UCs (exceto APAs), Terras Indígenas, Área Militar, perímetro urbano e massas d'água. Desse total de área cadastrável, 260712 hectares já se encontram devidamente registrados no Sistema de Cadastro Ambiental Rural - SICAR.

Os desmatamentos ocorridos em áreas de assentamento são componentes significativos do desmatamento ocorrido no município de Novo Repartimento como um todo, apesar da verificação da redução das taxas de desmatamento a partir de 2008 , de acordo com o comparativo a seguir: 


\begin{tabular}{|c|c|c|c|c|}
\hline Ano & $\begin{array}{c}\text { Taxas de } \\
\text { Desmatamento } \\
\text { em Novo } \\
\text { Repartimento (ha) }\end{array}$ & $\begin{array}{c}\text { \% Relativa à } \\
\text { Área Total do } \\
\text { Município }\end{array}$ & $\begin{array}{c}\text { Taxas de Desmatamento } \\
\text { em Assentamentos } \\
\text { de Novo Repartimento } \\
\text { (ha) }\end{array}$ & $\begin{array}{c}\text { \% Relativa à Área } \\
\text { Total de } \\
\text { Assentamentos }\end{array}$ \\
\hline 2009 & 29124 & 1,89 & 17651 & 4,68 \\
2010 & 21461 & 1,39 & 12496 & 3,32 \\
2011 & 18538 & 1,20 & 10019 & 2,66 \\
2012 & 12224 & 0,79 & 8198 & 2,18 \\
2013 & 15118 & 0,98 & 10233 & 2,72 \\
2014 & 7905 & 0,51 & 4868 & 1,29 \\
\hline
\end{tabular}

Tabela 1 - Taxas de Desmatamento no município e nos assentamentos de Novo Repartimento Fonte dos Dados: PRODES, 2015.

Apesar desse decréscimo, tanto a nível municipal quanto em seus assentamentos, tem-se que os resultados das análises de mudança do uso da terra em assentamentos no período de 2009 a 2014 mostram que 63465 hectares (16,8\% da área total de assentamentos) de cobertura florestal foram desmatados. Esse quantitativo corresponde a 60,8\% da área total desmatada no município no mesmo período. Essa realidade pode ser referendada pela pesquisa de Barroso e Alencar (2014), a qual afirma que o significativo número de assentamentos criados com a finalidade de resolver os problemas sociais no campo tem ocasionado consideráveis danos ao meio ambiente, uma vez que os assentados necessitam de área útil à implantação de suas atividades agropecuárias. Foi neste cenário que os assentamentos rurais representaram importante foco de desmatamento.

Com as evidências de que os projetos de assentamentos contribuem com o desmatamento ocorrido no município, além da necessidade em expandir o controle, monitoramento e o combate, procedeu-se a verificação do desenvolvimento do CAR como política pública e seus efeitos sobre o desmatamento nesta categoria fundiária.

A inscrição dos assentamentos de Reforma Agrária no CAR iniciou-se primeiramente com o registro do seu perímetro e posteriormente por meio da individualização dos lotes. Uma vez que se encontra vinculado a fatores sociais e ambientais, o CAR surge como um instrumento de monitoramento, fiscalização e execução em prol da conservação, tendo em vista diagnosticar o passivo ambiental em assentamentos. 
Em 2008, no início da vigência do CAR como instrumento da Política de Regularização Ambiental, Novo Repartimento totalizava apenas 1751 hectares em áreas sob registro no Cadastro Ambiental Rural, correspondendo a 0,14\% da área total cadastrável.

Já em 2009, verificou-se o início da adesão dos assentados ao Programa do CAR, quando registrou-se 6853 hectares de área dos projetos de assentamentos de Novo Repartimento inseridos no Sistema de Cadastro Ambiental Rural. A adesão foi crescente nos anos seguintes, chegando ao total de 260623 hectares, conforme apresentado na tabela 2.

\begin{tabular}{c|c|c|c|}
\hline Ano & $\begin{array}{c}\text { Áreas Inseridas } \\
\text { no CAR (ha) }\end{array}$ & $\begin{array}{c}\text { Áreas Inseridas } \\
\text { no CAR } \\
\text { Acumulado (ha) }\end{array}$ & $\begin{array}{c}\text { \% Relativa à Área Total } \\
\text { de Assentamentos }\end{array}$ \\
\hline 2009 & 6853 & 6853 & $1,82 \%$ \\
2010 & 29817 & 36670 & $9,73 \%$ \\
2011 & 10025 & 46695 & $12,39 \%$ \\
2012 & 49206 & 95901 & $25,45 \%$ \\
2013 & 73548 & 169449 & $44,97 \%$ \\
2014 & 91174 & 260623 & $69,17 \%$ \\
\hline
\end{tabular}

Tabela 2- Evolução do registro do CAR nos assentamentos de Novo Repartimento (PA) Fonte dos Dados: SEMAS, 2015.

Enquanto política de regularização ambiental e de combate ao desmatamento, infere-se que a grande quantidade de propriedades rurais (2.213) inscritos no Sistema do CAR, representando uma área de $69,17 \%$ do total de áreas dos assentamentos rurais de Novo Repartimento em 2014 permite o monitoramento e acompanhamento das atividades de uso da terra desenvolvidas pelos assentados rurais.

Ressalta-se aqui a importância da informação espacial fornecida pelo CAR. O registro por meio do CAR fornece informações essenciais sobre os imóveis rurais localizados em assentamentos, subsidiando assim ações preventivas, fiscalizatórias e punitivas por parte dos órgãos ambientais, tendo em vista a diminuição do passivo ambiental e conservação florestal. Informações como áreas de RL e APPs disponibilizadas pelo CAR são úteis para monitorar o desmatamento nessas áreas especiais e protegidas por lei, e também são capazes de subsidiar o planejamento de ações de políticas de conservação e de eventuais programas de pagamentos por serviços ambientais. Dados relativos ao uso alternativo do 
solo (UAS) poderiam também ser utilizados em conjunto com dados de produção agropecuária para dimensionar a agricultura familiar nestas áreas, bem como a proposição de alternativas logísticas para melhor armazenamento e distribuição dos produtos originários de assentamentos rurais.

Para o período em análise, 2009 a 2014, a adesão do CAR foi significativa e crescente como demonstrado na tabela 2 e na figura 4, que representa a quantidade anual de CAR inseridos no Sistema SIMLAM, somente nas áreas dos assentamentos rurais de Novo Repartimento.
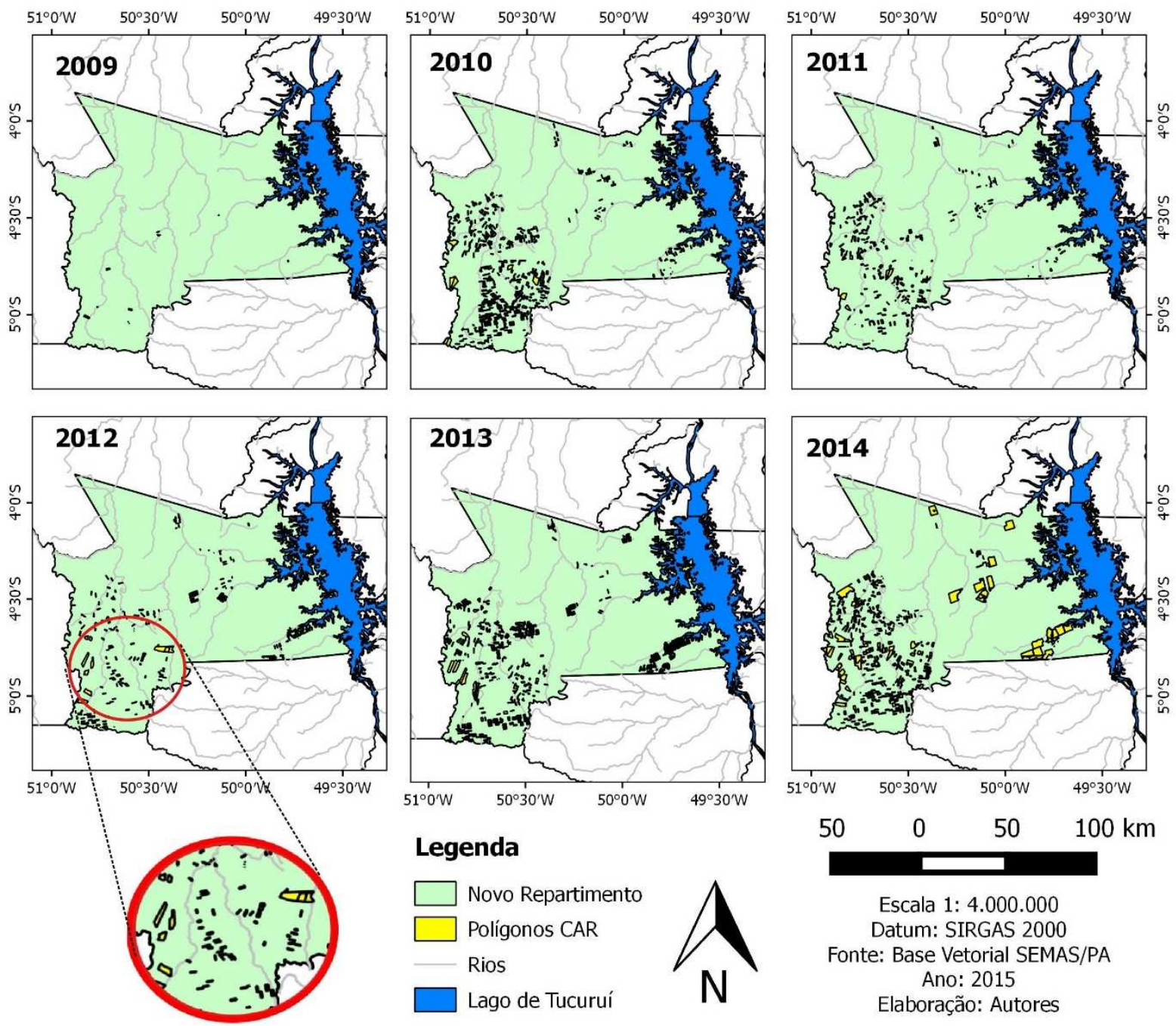

\section{Legenda}
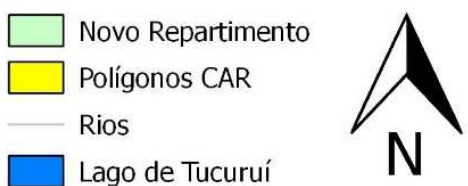

Detalhe dos polígonos de CAR

Figura 2- Evolução do CAR em Assentamentos de Novo Repartimento (2009-2014) Fonte dos Dados: SEMAS/PA, 2015.

Percebe-se que no primeiro ano em análise, a adesão foi tímida, tendo uma forte adesão nos anos seguintes, especialmente 2010, 2013 e 2014, sendo que nestes últimos pode ter sido devido à grande mobilização que órgãos federais e estaduais, além de ONGs voltadas 
ao tema ambiental, fizeram para incentivar a adesão ao CAR. Além da vigência do Novo Código Florestal, que prevê o CAR como instrumento de Política Pública Ambiental, muitos proprietários rurais dentro e fora dos assentamentos rurais começaram a perceber os benefícios de ter o registro do CAR de sua propriedade.
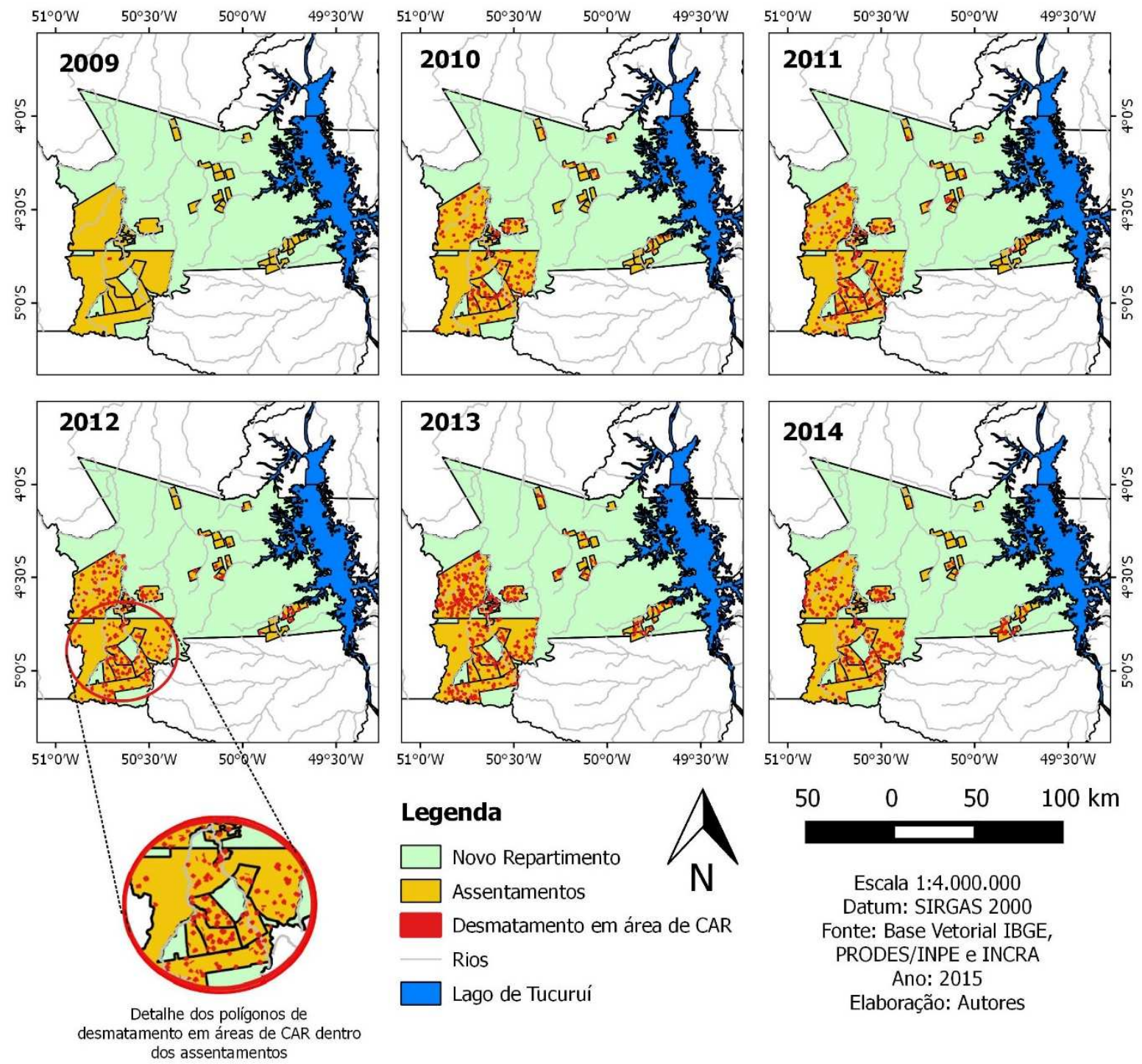

Figura 3- Evolução do Desmatamento Ocorrido em Áreas de CAR em Assentamentos de Novo Repartimento (2009-2014)

Fonte dos Dados: INPE/ INCRA, 2015.

Assim, para verificar a efetividade do Cadastro Ambiental Rural (CAR) como política ambiental em projetos de assentamentos, iniciou-se a análise da incidência do desmatamento em áreas com e sem o registro do CAR, conforme demonstrado na figura 3 e na tabela 3, cujos valores foram obtidos a partir de análises de geoprocessamento: 


\begin{tabular}{|c|c|c|c|c|c|c|}
\hline \multicolumn{7}{|c|}{ Desmatamento } \\
\hline \multirow[b]{2}{*}{ Ano } & \multirow[b]{2}{*}{$\begin{array}{c}\text { Área Inserida } \\
\text { no CAR (ha)- } \\
\text { Acumulado }\end{array}$} & \multirow[b]{2}{*}{$\begin{array}{c}\text { Em Áreas de } \\
\text { assentamento } \\
\text { (ha) }\end{array}$} & \multicolumn{2}{|c|}{ Com CAR } & \multicolumn{2}{|c|}{ SEM CAR } \\
\hline & & & $\begin{array}{c}\text { Em áreas de } \\
\text { assentamento } \\
\text { cadastradas (ha) }\end{array}$ & $\begin{array}{c}\% \\
\text { Relativa }\end{array}$ & $\begin{array}{c}\text { Em áreas de } \\
\text { assentamento } \\
\text { não cadastradas } \\
\text { (ha) }\end{array}$ & $\begin{array}{c}\% \\
\text { Relativa }\end{array}$ \\
\hline 2009 & 6853 & 17651 & 13 & $0.07 \%$ & 17638 & $99,93 \%$ \\
\hline 2010 & 36670 & 12496 & 1491 & $11,93 \%$ & 11005 & $88,07 \%$ \\
\hline 2011 & 46695 & 10019 & 1789 & $17,86 \%$ & 8230 & $82,14 \%$ \\
\hline 2012 & 95901 & 8198 & 2175 & $26,53 \%$ & 6023 & $73,47 \%$ \\
\hline 2013 & 169449 & 10233 & 5881 & $57,47 \%$ & 4352 & $42,53 \%$ \\
\hline 2014 & 260623 & 4868 & 2831 & $58,16 \%$ & 2037 & $41,84 \%$ \\
\hline
\end{tabular}

Tabela 3- Desmatamento em Áreas de Assentamentos Com e Sem CAR

Fonte dos Dados: PRODES/ SEMAS-PA, 2015.

No período analisado foi possível observar reduções sucessivas nas taxas de desmatamento ocorridas em áreas de assentamentos. Os assentamentos, apesar de exercerem grande influência em relação ao desmatamento da região, não são os únicos agentes responsáveis. Com efeito, análises da sua contribuição para a dinâmica anual do desmatamento mostram que, mesmo aumentando em número e em área, eles têm acompanhado a mesma tendência de queda que vem ocorrendo na Amazônia, no Estado e no município como um todo.

Da mesma forma que as taxas de desmatamento foram decrescendo, a adesão ao CAR foi aumentando, conforme mostra a tabela 3. Com os dados de áreas inseridas no CAR e as ocorrências de desmatamento ano a ano, foi possível estimar a sua proporção ocorrida em áreas inseridas no CAR, a fim de avaliar sua efetividade como política ambiental de regularização ambiental.

Assim, as áreas de assentamentos rurais inseridas no CAR totalizaram até o ano de 2014, 260623 ha. Ocorrências de desmatamento medidas pelo PRODES/INPE no período de 2009 a 2014 foram registradas em áreas com e sem CAR. Vale ressaltar que ocorreu uma adesão gradativa do CAR no período em análise, o que refletiu nos valores percentuais relativos ao total de desmatamento registrado, os quais foram crescendo na medida que mais áreas estavam cadastradas, aumentando, portanto, a probabilidade de que os desmatamentos ocorressem em áreas com CAR. 
No ano de 2014, do total de área desmatada em áreas de assentamentos, 58,16\% foram em áreas com CAR, e 41,84\% em áreas não registradas. Embora a princípio, esperava-se que as áreas com CAR tivessem menores incidências de desmatamento, dados apontaram uma ocorrência maior em áreas com CAR. Como possível justificativa, tem-se que as áreas que tiveram maior adesão ao CAR, foram aquelas que mais precisavam regularizar suas atividades rurais, as quais muitas vezes prescindiam de modificações no uso da terra, para adequação às atividades de agricultura ou pecuária.

Neste contexto, as mudanças no uso e cobertura da terra, notadamente o desmatamento ocorrido nas áreas de assentamento, podem estar associadas às atividades próprias de assentamentos rurais economicamente produtivos. Além disso, o CAR oferece a possibilidade de certificar as propriedades rurais que comercializam produtos agrícolas, pois só estarão aptas aquelas que estiverem de acordo com a legislação ambiental brasileira, a qual proíbe desmatamento sem licenciamento.

De fato, políticas estaduais tais como o Plano de Prevenção, Controle e Alternativas ao Desmatamento do Estado do Pará (PPCAD-PARÁ), o Acordo pelo Desmatamento Zero firmado com o Ministério Público Federal e o Programa Municípios Verdes, tem incentivado a atividade rural ambientalmente sustentável e tem ajudado a consolidar o CAR como ferramenta de diagnóstico do passivo ambiental em propriedades rurais, atuando assim na fiscalização e conservação do meio ambiente.

\section{Considerações finais}

A partir do desenvolvimento desta pesquisa, pôde-se verificar que os processos de mudança do uso da terra, particularmente o desmatamento, em áreas de projetos de assentamentos agrários tem significativa contribuição ao total registrado para o município de Novo Repartimento.

A partir da detecção que, no período de 2009 a 2014, 63465 hectares de desmatamentos ocorreram em áreas de assentamentos, tem-se associado os projetos de Reforma Agrária como um dos principais responsáveis pelo processo de conversão florestal no município. 
Entretanto, constatou-se um esforço quanto à regularização ambiental dessas áreas, verificado a partir do crescimento na adesão dos assentados ao Cadastro Ambiental Rural. No ano de 2009, os assentamentos de Novo Repartimento detinham apenas 6853 hectares em áreas registradas através do Cadastro Ambiental Rural (CAR), correspondendo a 0,14\% da área total cadastrável; já em 2014, o número de áreas cadastradas subiu para 260623 hectares, sendo que 91174 hectares em áreas de assentamentos, representando 69,17\% de sua área total.

Também é importante ressaltar que o reforço de políticas estaduais, tais como o Plano de Prevenção, Controle e Alternativas ao Desmatamento do Estado do Pará (PPCAD-PARÁ), o Acordo pelo Desmatamento Zero firmado com o Ministério Público Federal e o Programa Municípios Verdes, fortaleceram o desenvolvimento do CAR como ferramenta de diagnóstico do passivo ambiental em propriedades rurais, atuando assim na fiscalização e conservação do meio ambiente.

Assim, pode-se definir o CAR como um instrumento importante de gestão ambiental rural, atuando no controle, monitoramento e o combate ao desmatamento em assentamentos no município de Novo Repartimento, mas não é possível declarar que a ocorrência desse desmatamento é ilegal, sendo necessário assim estudos futuros que analisem onde ocorre as maiores incidências.

É possível afirmar que as atividades produtivas em áreas de assentamentos contribuem para a mudança do uso da terra, mas essa análise não pode considerar este como um modelo desenvolvido pela agricultura familiar como exploratório e/ou desmatador, uma vez que torna-se imprescindível o conhecimento associado das formas de obtenção dessas áreas, história de desenvolvimento e desafios enfrentados para manutenção da unidade familiar.

\section{Referências bibliográficas}

ACSELRAD, H. Planejamento autoritário e desordem socioambiental na Amazônia: crônica do deslocamento de populações em Tucuruí. Revista de Administração Pública, v. 25, n. 4, p. 53-68, 1991.

ACSELRAD, H. Mercado de terras e meio ambiente em áreas de grandes projetos de investimento: o caso da Usina Hidrelétrica de Tucuruí. Estudos Sociedade e Agricultura, v. 2, 2010. 
ASSUNÇÃO, J.; GANDOUR, C.; PESSOA, P.; ROCHA, R. Deforestation Scale and Farm Size: The Need for Tailoring Policy in Brazil. Rio de Janeiro: Climate Policy Initiative, 2015, 29 p.

AZEVEdO, A. A.; RAJÃO, R.; COSTA, M.; STABILE, M. C. C.; ALENCAR, A.; MOUTINHO, P. Cadastro Ambiental Rural e sua influência na dinâmica do desmatamento na Amazônia Legal. Brasília: IPAM, 2014, 16 p.

BARROSO, L. A.; ALENCAR, G. V. O Cadastro Ambiental Rural (CAR) como instrumento de regularização ambiental em assentamentos de reforma agrária. Revista Brasileira de Gestão Ambiental e Sustentabilidade, v. 1, n. 1, p. 5-13, 2014.

BATISTELLA, M.; MORAN, E. F. Dimensões humanas do uso e cobertura das terras na Amazônia: uma contribuição do LBA. Acta Amazônica, v. 35, n. 2, 2005.

CALANDINO, D.; WEHRMANN, M.; KOBLITZ, R. Contribuição dos assentamentos rurais no desmatamento da Amazônia: um olhar sobre o Estado do Pará. Desenvolvimento e Meio Ambiente, v. $26,2012$.

CARNEIRO, M. S.; ASSIS, W. S. O controle do desmatamento na Amazônia como um processo de modernização ecológica: a experiência do Projeto Município Verde. Revista Pós Ciências Sociais, v. 12, n. 24, 2015.

CASTRO, E. R.; MARIN, R. A.; SZLAFSZTEIN, C.; COSTA, E. J. M.; RAVENA, N.; ROCHA, G. M.; ANDRADE, L. G.; SILVA, I. M. C.; FERNANDES, F. A. Estudo Socioeconômico dos Municípios da Região de Tucuruí, Pará. Papers NAEA, n. 258, 2010.

CAVIGLIA-HARRIS, J.; HARRIS, D. The impact of settlement design on tropical deforestation rates and resulting land cover patterns. Agricultural and Resource Economics Review, v. 40, n. 3, p. 451, 2011.

CAVIGLIA-HARRIS, J.; SILLS, E.; BELL, A.; HARRIS, D.; MULLAN, K.; ROBERTS, D. Busting the Boom-Bust Pattern of Development in the Brazilian Amazon. World Development, v. 79, p. 82-96, 2016.

CÔRTES, Julia Correa et al. Ciclo de vida familiar e distribuição populacional na dinâmica do desmatamento e uso da terra na Amazônia paraense. Tese de Doutorado - Universidade Estadual de Campinas, Instituto de Filosofia e Ciências Humanas, 2017.

DIAS, L. F. O.; DIAS, D. V.; MAGNUSSON, W. E. Influence of Environmental Governance on Deforestation in Municipalities of the Brazilian Amazon. PloS one, v. 10, n. 7, p. e0131425, 2015.

DINIZ, M. B.; OLIVEIRA JUNIOR, J. N. D.; TROMPIERI NETO, N.; DINIZ, M. J. T. Causas do desmatamento da Amazônia: uma aplicação do teste de causalidade de Granger acerca das principais fontes de desmatamento nos municípios da Amazônia Legal brasileira. Nova Economia, v. 19, n. 1, p. 121-151, 2009.

DINIZ, F. H.; KOK, K.; HOOGSTRA-KLEIN, M. A.; ARTS, B. Mapping future changes in livelihood security and environmental sustainability based on perceptions of small farmers in the Brazilian Amazon. Ecology and Society, v. 20, n. 2, p. 26, 2015.

FUNDAÇÃO AMAZÔNIA DE AMPARO A ESTUDOS E PESQUISAS DO PARÁ. Boletim Agropecuário do Estado do Pará 2015. Belém: FAPESPA, 2015, 38 p.

HARGRAVE, J.; KIS-KATOS, K. Economic causes of deforestation in the Brazilian Amazon: a panel data analysis for the 2000s. Environmental and Resource Economics, v. 54, n. 4, p. 471-494, 2013.

INSTITUTO DE DESENVOLVIMENTO ECONÔMICO, SOCIAL E AMBIENTALDO PARÁ (IDESP). Indicadores de Qualidade Ambiental dos Municípios da Região de Integração Lago de Tucuruí. Belém: IDESP, 2013, 44 p.

INSTITUTO DO HOMEM E MEIO AMBIENTE DA AMAZÔNIA (IMAZON). Desmatamento e degradação florestal em Novo Repartimento- Pará. Belém: IMAZON, 2014, 2 p.

MELLO-THÉRY, N. A. Território e Gestão Ambiental na Amazônia: Terras Públicas e os Dilemas do Estado. São Paulo: Ed. Annablume, 2011, 200 p.

OLIVEIRA JÚNIOR, J. N. D.; DINIZ, M. B.; FERREIRA, R. T.; CASTELAR, I.; DINIZ, M. J. T. Análise da área desmatada municipal na Amazônia brasileira no período 2000-2004: uma abordagem com modelos não lineares. Economia Aplicada, v. 14, n. 3, p. 395-411, 2010.

PACHECO, P.; AGUILAR-STOEN, M.; BÖRNER, J.; ETTER, A.; PUTZEL, L.; DIAZ, M. D. C. V. Landscape transformation in tropical Latin America: assessing trends and policy implications for REDD+. Forests, v. 2, n. 1, p. 1-29, 2010. 
PARÁ. Decreto № 1.697, de 5 de Junho de 2009. Institui o Plano de Prevenção, Controle e Alternativas ao Desmatamento do Estado do Pará, e dá outras providências. Diário Oficial do Estado do Pará, №. 31435, de 08 de junho de 2009.

PARÁ. Portaria SEMAS № 654, de 07 de abril de 2016. Dispõe sobre a implementação do Sistema Nacional de Cadastro Ambiental Rural - SICAR como o Sistema Oficial de Cadastro Ambiental do Estado do Pará, que será denominado - SICAR/PA. Diário Oficial do Estado do Pará, №. 33104, de 07 de abril de 2016.

PIKETTY, M. G.; DRIGO, I.; SABLAYROlleS, P.; AQUINO, E. A.; PENA, D.; SIST, P. Annual Cash Income from Community Forest Management in the Brazilian Amazon: Challenges for the Future. Forests, v. 6, n. 11, p. 4228-4244, 2015.

RODRIGUES-FILHO, S.; VERBURG, R.; BURSZTYN, M.; LINDOSO, D.; DEBORTOLI, N.; VILHENA, A. M. Electiondriven weakening of deforestation control in the Brazilian Amazon. Land Use Policy, v. 43, p. 111-118, 2015.

ROCHA, G. M. Usinas Hidrelétricas e Mudanças Demográficas na Amazônia Brasileira. Revista Eletrônica de Geografia Austral, v. 7, n. 1, 2015.

ROSA, I. M.; PURVES, D.; CARREIRAS, J. M.; EWERS, R. M. Modelling land cover change in the Brazilian Amazon: temporal changes in drivers and calibration issues. Regional environmental change, v. 15, n. 1, p. 123-137, 2015.

SANTOS, L. A. C.; BATISTA, A. C.; NEVES, C. O. M.; CARVAlho, E. V.; SANTOS, M. M.; GiOngO, M. Análise multitemporal do uso e cobertura da terra em nove municípios do Sul do Tocantins, utilizando imagens Landsat. Revista Agro@ mbiente On-line, v. 11, n. 2, p. 111-118, 2017.

SCHNEIDER, M.; PERES, C. A. Environmental Costs of Government-Sponsored Agrarian Settlements in Brazilian Amazonia. PloS one, v. 10, n. 8, 2015.

SILVA, M. G. Reordenamento territorial e transformações socioecológicas e culturais: lições adversas da construção da UHE Tucuruí/ PA. Revista Sentidos da Cultura, v. 1, n. 1, p. 17-20, 2014.

SILVA, T. V.; QUEIROZ, T. M.; GALVANIN, E. S. Uso da Terra no Assentamento Antônio Conselheiro no Estado de Mato Grosso. Raega-O Espaço Geográfico em Análise, v. 40, p. 35-44, 2017.

SONG, X. P.; HUANG, C.; SAATCHI, S. S.; HANSEN, M. C.; TOWNSHEND, J. R. Annual Carbon Emissions from Deforestation in the Amazon Basin between 2000 and 2010. PloS one, v. 10, n. 5, 2015. 